\title{
RELATION OF SIZE AND ACTIVITY OF MOTOR CORTEX PYRAMIDAL TRACT NEURONS DURING SKILLED MOVEMENTS IN THE MONKEY
}

\author{
CHRISTOPH FROMM ${ }^{1}$ AND EDWARD V. EVARTS
}

Laboratory of Neurophysiology, National Institute of Mental Health, Rethesda, Maryland 20205

\begin{abstract}
Activity of motor cortex pyramidal tract neurons (PTNs) was recorded in monkeys making large $\left(20^{\circ}\right)$, high velocity and small $\left(1\right.$ to $\left.2^{\circ}\right)$, low velocity pronation-supination arm movements in a visual pursuit-tracking paradigm. Antidromic response latencies (ADLs) of PTNs were examined in relation to PTN modulation with the large and small movements to test the hypothesis that PTNs would exhibit a "size principle" analogous to that of spinal cord motoneurons. It was found that smaller PTNs (i.e., those having longer ADLs) discharged just as strongly with small, slow movements as with large, fast movements, while about one-third of the larger PTNs (even those selected for a significant relation to small movement) discharged more intensely with the large movement. Another analysis dealing with PTNs in a selected set of penetrations in an area focal for pronation-supination showed that PTNs with longer ADLs (>1 msec) were more likely to reach maximum frequency with small, slow movement. There was, however, much overlap in the behavior of small and large PTNs, and while there was a statistically significant relation between size and movement-related activity of PTNs, there did not seem to be a "size principle" in the strict sense that this term has been used with reference to spinal cord motoneurons.
\end{abstract}

During small, low velocity movements involving activity of relatively few $\alpha$ motoneurons (MNs), smaller MNs tend to be active and larger MNs tend to be silent, whereas for larger, high velocity movements involving intense muscular activity, there is discharge of both large and small MNs. Thus, small MNs innervating small fatigue-resistant motor units tend to be active with both small and large movements, while large MNs innervating more powerful fast fatigue motor units (cf., Henneman et al., 1965; Burke, 1973) fail to become active with small movements but do discharge with large ones. In the present study, we sought to determine the extent to which there might be an analogous relation between size and movement-related activity in motor cortex pyramidal tract neurons (PTNs). The antidromic response latencies (ADLs) of the PTNs served as a basis for inferences as to relative size within the PTN sample: PTNs having shorter ADLs were categorized as larger and those having longer ADLs were categorized as smaller.

Our results indicate that, while there is a statistically significant relation between size and movement-related activity in PTNs, this relation is not nearly so strong as the relation for spinal cord MNs. Indeed, there are many instances in which PTNs with the very shortest ADLs

\footnotetext{
${ }^{1}$ Fellow of the Deutsche Forschungsgemeinschaft (Heisenberg Program).
}

are modulated intensely and use their full dynamic frequency range for extremely small movements. Preliminary reports describing certain of these findings have appeared (Fromm and Evarts, 1977; Evarts and Fromm, 1978).

\section{Materials and Methods}

A visual pursuit tracking paradigm was used for training two monkeys to position a handle within a small zone and to rotate it by pronation-supination movements of the arm. 'The monkey viewed two horizontal rows of lamps. One row (the "track" row) informed the monkey as to the actual handle orientation. The second row of lamps (the "target" row, directly beneath the track row) signaled what the handle position should have been. A handle movement of $1.5^{\circ}$ shifted the track lamp from one position to an adjacent position. The task of the monkey was to hold the handle in a given $1.5^{\circ}$ zone in order to maintain alignment of the target lamp and the track lamp. When there was a misalignment, the monkey moved the handle so that realignment was achieved. Usually the misalignments were slight and the monkey moved the handle from one narrow zone to the next by very small ( 1 to $2^{\circ}$ ) pronations or supinations in order to realign the track and target lamps. Such small movements were necessitated sometimes by the monkey's failure to keep the handle still. At other times what 
appeared as misalignments to the monkey were produced by an external signal added to the output of the position transducer which controlled the track display. The result of this added signal (a shift of the track lamp) appeared to the monkey to result from an incorrect handle position and led to a small corrective movement. For comparison with the small movements referred to above, large amplitude, high velocity supination-pronation movements ( $20^{\circ}$ angular displacement) were induced by a jump of the target to the extreme right or left. These large movements usually exhibited a single velocity stroke which was 20 to 30 times greater than the peak velocities occurring for the fine movements. Immediately after this movement, the monkey returned the handle to the vertical position to begin a new sequence. The durations of holding periods prior to large or small triggered movements and the directions of the triggered movements were varied according to a predetermined random order. The handle grasped by the monkey was coupled to the shaft of a DC torque motor which produced a constant torque requiring either steady supinator or pronator force. In addition, brief $5^{\circ}$ pronating or supinating displacements were delivered to the handle to study unit responses to kinesthetic inputs.

For antidromic identification of PTNs, a bipolar stimulating electrode was implanted permanently in the medullary pyramid $2 \mathrm{~mm}$ posterior to the zero reference in the Horsley-Clarke coordinate system. In one monkey, the electrode was placed beside rather than within the pyramid, while, in the other monkey, the stimulating electrode was positioned exactly within the center of the pyramidal tract, resulting in a correspondingly higher yield of more slowly conducting P'TNs. For the poorly placed electrode, an increase of stimulus strength led to a larger stimulus artifact and to the occurrence of synaptically evoked responses due to excitation of the nearby medial lemniscus with resultant orthodromic responses which interfered with identification of PTNs. A neuron was identified as a PTN when its response to pyramidal tract stimulation followed each shock of a five-shock high frequency $(>200 \mathrm{~Hz})$ train with a constant antidromic latency $(\mathrm{ADL})$ and when its response was absent following a collision with a spontaneously occurring spike. The ADL of each PTN (measured from stimulus onset to first deflection of the evoked spike) was observed at threshold and suprathreshold stimulation.

Data recording and processing. Single unit activity contralateral to the arm used by the monkey was recorded employing standard procedures (Evarts, 1968). The recording cylinder allowed penetrations within a 16$\mathrm{mm}$ diameter circular region located over the arm area of primary motor cortex. Unit discharge, discriminator pulses, handle position and velocity, and code signals corresponding to stimulus and response events of the paradigm were recorded on magnetic tape. A PDP-12 computer was used for analysis of neural activity and display in the form of rasters (each row is a trial, dots representing spikes), of time histograms (average discharge frequency in hertz for 10-msec bin widths), and of computed neural response latencies. A neural response in relation to movement or torque pulse was defined as a deviation from control frequency values in the peri- response displays at the $p<0.01$ level of statistical significance (cf., Tanji and Evarts, 1976). Surface electromyogram (EMG) was recorded from several muscles of the arm, rectified, and fed to a voltage-to-frequency converter (Teledyne-Philbrick; frequency range, 0 to $1000 \mathrm{~Hz}$ ) whose output pulses were analyzed and displayed in the same manner as the neural impulses.

Histology. After completion of the recordings, the animals were perfused with physiological saline and $10 \%$ formalin. Five marks corresponding to the center and extreme coordinates of the penetration map were made in the cortex. The fixed brain was removed and a photograph taken perpendicularly to the brain surface was enlarged in order to match the reference points of the coordinates map of the recording system. Penetration sites were located mainly in relation to surface structures and reconstructed from sagittal serial sections $(50 \mu \mathrm{m})$ stained with thionine.

\section{Results}

Two hundred eighty precentral arm area PTNs were studied systematically in two monkeys, and upon subsequent statistical analysis, 156 of these were found to meet the statistical criteria of being related to the supinationpronation movements performed in this paradigm. Eighty-five of these 156 PTNs were modulated for the small $\left(1.5^{\circ}\right)$ movements, while the remaining 71 of the 156 related units failed to exhibit changes in discharge frequency for small movements but were modulated for the larger $\left(20^{\circ}\right)$, high velocity movements. A consideration of the contrasting properties of these two categories of PTNs will be a continuing theme in our presentation of results, and for simplicity, we will refer to them as small movement related (SM) and large movement related (LM). All of the SM PTNs (defined by their participation in the small movement) also participated in control of the large movement, whereas LM PTNs were, by definition, those which participated in control of the large movement but failed to participate in control of the small movement. It should be noted that the definition of SM PTNs did not require that they also participate in control of the large movement, and one of our most consistent and significant findings was the invariable modulation with large movements by those PTNs which had exhibited modulation with small movements.

The distribution of SM and LM units within three PTN groups formed on the basis of an arbitrary categorization of antidromic response latency (ADL) is illustrated in Figure 1, showing that there were equal numbers of SM (49) and LM (50) PTNs in the group of large PTNs (ADL $\leq 1 \mathrm{msec}$ ), somewhat more SM (18) than LM (12) units in the group of PTNs with intermediate ADLs, and twice as many SM (18) as LM (9) PTNs in the group of small PTNs (ADL $\geq 2$ msec). While suggestive, this trend, as tested by $\chi^{2}$, failed to reach statistical significance $(p>0.05)$.

The basis for classifying PTNs as SM in Figure 1 was the presence of a statistically significant change in discharge frequency with small movement, but another and perhaps a more sensitive way to look for a relation between ADL and modulation of PTN discharge with movement involves comparing peak discharge frequency 


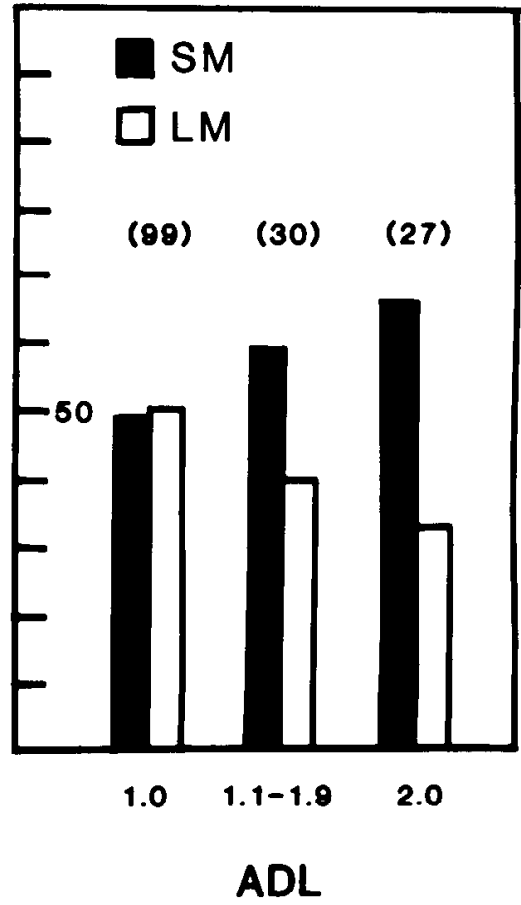

Figure 1. PTNs that are small movement related (SM) and large movement related (LM) classified according to ADL. The 156 PTNs related to movement have been divided into three arbitrary ADL classes to show proportions of SM (black bars) and LM (white bars) units within each class. The numbers of PTNs in each class are indicated by the numbers in parenthe. ses. The ordinate scale shows the percentage of each class. Thus, of 99 PTNs with $\mathrm{ADL} \leq 1 \mathrm{msec}, 49 \%$ were $\mathrm{SM}$ and $51 \%$ were LM, while $67 \%$ of 27 PTNs with ADL $\geq 2$ msec were SM and only $33 \%$ were LM.

with small and large movements within the group of SM units. Examination of the data in this way seemed appropriate in view of the fact that individual motor units in man discharge with progressively higher peak frequencies with increases of amplitude and speed of isometric (Desmedt and Godaux, 1977) or isotonic (Freund and Büdingen, 1978) muscular contractions.

For purposes of relating ADL to differences between peak frequency with small $\left(\mathrm{PF}_{\mathrm{S}}\right)$ and peak frequency with large $\left(\mathrm{PF}_{\mathrm{L}}\right)$ movement, the $85 \mathrm{SM} \mathrm{PTN}$ were divided into three groups according to the relation between $\mathrm{PF}_{\mathrm{S}}$ and $\mathrm{PF}_{\mathrm{L}}$ : (1) If the difference between the two scores was less than half of the smaller of the two scores, the scores were classified as approximately equal $\left(\mathrm{PF}_{S}\right.$ $=P F_{L}$ ). (2) If $P F_{L}$ exceeded $P F_{S}$ by at least half of $P F_{S}$, the $\mathrm{PF}_{\mathrm{L}}$ score was classified as greater than the $\mathrm{PF}_{\mathrm{S}}$ score $\left(P F_{L}>P F_{S}\right)$. (3) If $P F_{S}$ exceeded $P F_{L}$ by at least half of $\mathrm{PF}_{\mathrm{L}}$, the $\mathrm{PF}_{\mathrm{S}}$ score was classified as greater than the $\mathrm{PF}_{\mathrm{L}}$ score $\left(\mathrm{PF}_{\mathrm{S}}>\mathrm{PF}_{\mathrm{L}}\right)$. Figure 2 shows unit discharge, displacement, and biceps EMG associated with large and small movements. A 1.0 -msec ADL PTN with $\mathrm{PF}_{\mathrm{L}}>\mathrm{PF}_{\mathrm{S}}$ is shown at the upper left. This relation was the most common among PTNs showing differences between $\mathrm{PF}_{\mathrm{L}}$ and $\mathrm{PF}_{\mathrm{S}}$. The opposite and least common relation $\left(\mathrm{PF}_{\mathrm{S}}\right.$ $>\mathrm{PF}_{\mathrm{L}}$ ) is also shown in Figure 2 for a PTN with ADL $=4.4$ msec. $\mathrm{A}$ lack of difference between $\mathrm{PF}_{\mathrm{S}}$ and $P \mathrm{PF}_{\mathrm{L}}$ is shown for two PTNs (ADL $=2.0 \mathrm{msec}$ and $2.2 \mathrm{msec}$ ).
Figure 2 also shows that PTN discharge built up more gradually and lasted longer for the small than for the large movement and that the magnitude of the biceps discharge was very much less for the small supination than for the large (lower right). Figure 2 also illustrates a PTN with $\mathrm{ADL}=3.6 \mathrm{msec}$ which failed to show any modulation with small movement and had only a weak relation to the large one (this PTN was classified as an LM unit). This weak relation is commented on because the PTN was in the focal region for pronation-supination and was surrounded by highly related SM PTNs; several other focally located PTNs with ADLs between 3.0 and $4.0 \mathrm{msec}$ showed a similar lack of modulation with the small movement (see penetrations $A, D$, and $G$ in Fig. 3 ).

Table I $A$ (based on the classifications referred to above) reveals several interactions between $\mathrm{PF}$ and ADL. First, it may be seen that 16 of the 19 PTNs with $\mathrm{PF}_{\mathrm{L}}>$ $\mathrm{PF}_{\mathrm{S}}$ had ADLs $\leq 1 \mathrm{msec}$ and that only 3 had ADLs $>1$ msec, while units with $\mathrm{PF}_{\mathrm{L}} \leq \mathrm{PF}_{\mathrm{S}}$ were equally distributed in the two ADL categories (33 with ADLs $\leq 1 \mathrm{msec}$ and 33 with ADLs $>1 \mathrm{msec}$ ). This difference was statistically significant $\left(\chi^{2}=7.07 ; p<0.001\right)$. Table $I B$ gives the results of a further breakdown of the 85 units according to three ADL categories and three relations between $\mathrm{PF}_{\mathrm{L}}$ and $\mathrm{PF}_{\mathrm{S}}$ and shows that, of the $18 \mathrm{PTNs}$ with $\mathrm{ADL}$ $\geq 2$ msec, only 1 showed $P_{L}>P F_{S}$, while 16 of the 49 units with $\mathrm{ADL} \leq 1$ msec showed $\mathrm{PF}_{\mathrm{L}}>\mathrm{PF}_{\mathrm{S}}$. Thus, units showing more intense discharge for large than for small movements tend to belong to the category of large PTNs. The number of units with $\mathrm{PF}_{\mathrm{S}}>\mathrm{PF}_{\mathrm{L}}$ was rather small (only 9 of the 85 PTNs) and was rarer in PTNs with $\mathrm{ADL} \leq 1 \mathrm{msec}\left({ }^{3 / 49}\right)$ than in PTNs with ADL $>1 \mathrm{msec}$ $(6 / 36)$. Table $I B$ also gives mean values for peak frequencies of SM PTNs. The standard deviation within each group was considerable and there were no significant differences between means, but the trend was for PTNs with $\mathrm{ADL} \geq 2.0 \mathrm{msec}$ to reach higher peak frequencies than PTNs with ADL $<2.0 \mathrm{msec}$. In connection with this group of 85 SM PTNs, it is to be noted that $80 \%$ of them were encountered in penetrations within a focal area of $1.5 \mathrm{~mm}$ diameter located $2 \mathrm{~mm}$ anterior to the central fissure and that the stereotaxic coordinates of the focal area were approximately the same in the two monkeys. As will be pointed out in a subsequent section of this report, units within this focal area had a high probability of responding to afferent inputs generated by passively produced pronation-supination. Furthermore, intracortical microstimulation within the focal area produced pronation or supination movements of the arm.

A third examination of the relation of ADL to PTN activity with movement was made by considering all PTNs recorded in a set of microelectrode penetrations restricted to the above-described focal area for pronationsupination. Eleven of the penetrations within this zone yielded at least two systematically studied PTNs of which at least one was related to small movement, and the results for all of the 52 PTNs picked up in these 11 penetrations are summarized in Table II and Figure 3. Units were included in these analyses regardless of whether they were SM, LM, or unrelated. Figure 3 shows the arrangement of the PTNs within these penetrations yielding the 52 units considered in Table II. Table II 

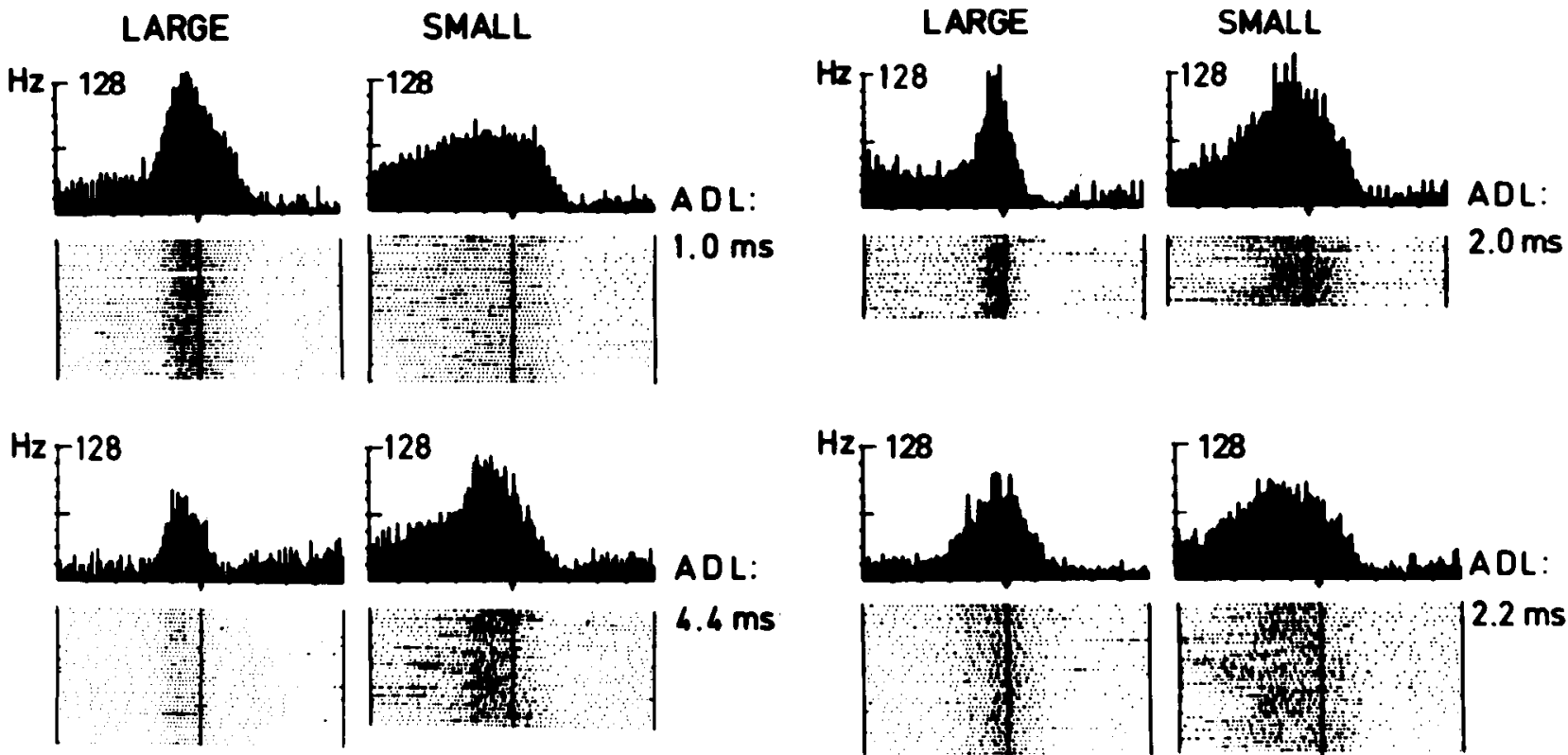

ADL:
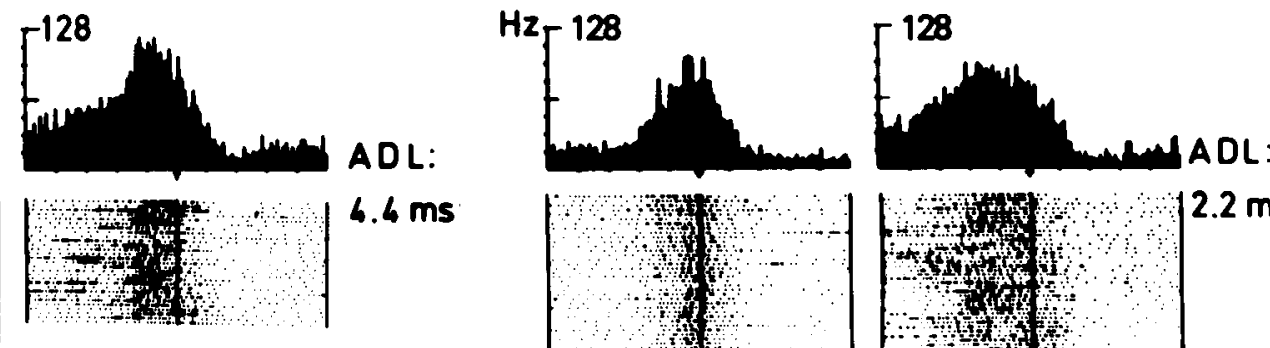

$6.4 \mathrm{~ms}$
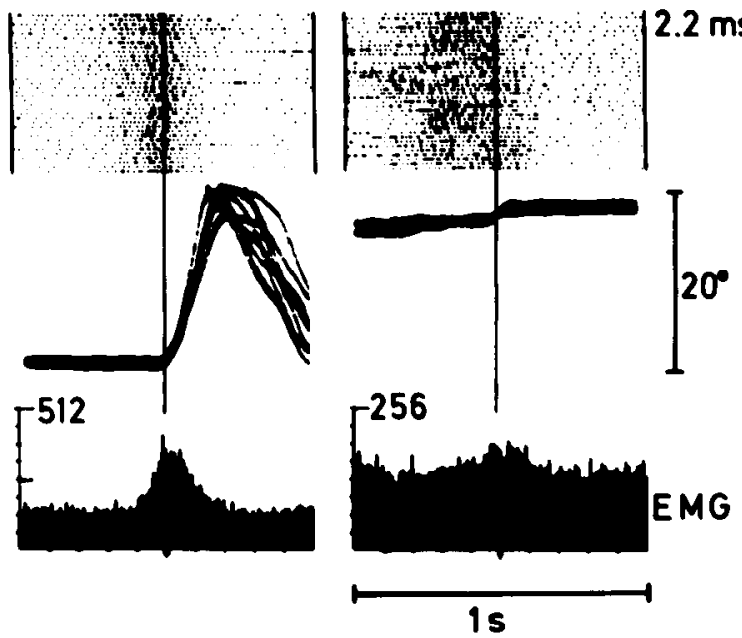

Figure 2. PTN discharge pattern with large and small movements. The activity of each PTN is shown in rasters and histograms (average discharge frequency in hertz, computed for $10-\mathrm{msec}$ bins) for the large and small movement, respectively. All P'TNs were related reciprocally to both directions of movement; the three PTNs on the left side increased firing with pronation, whereas for the two PTNs on the right, activity increased with supination. The center line in all plots marks the time at which the handle leaves the hold zone; for the small movements, this moment is identical with the handle entering the correct zone to realign track and target lamp. In addition, superimposed position records (upward deflection = supination) and the corresponding surface EMG of biceps are depicted (note the different scales of the EMG histograms). The background activity of the EMG is due to steady load-opposing supination. The same time scale $(1 \mathrm{sec})$ applies to all plots.

\section{TABLE I}

Peak frequency for small $\left(P F_{S}\right)$ and large $\left(P F_{L}\right)$ movements in 85 SM PTNs

The 85 SM PTNs have been categorized according to peak frequency with large movement $\left(\mathrm{PF}_{\mathrm{L}}\right)$ and peak frequency with small movement (PFs) and according to ADL. In $A$, two categorizations are used for each dimension, while in $B$, there is a further breakdown. For details of PFs and $P F_{L}$ categorization criteria and results of statistical analysis, see text.

\begin{tabular}{ccc}
\multicolumn{3}{c}{$A$} \\
\hline ADL & $\mathrm{PF}_{\mathrm{S}} \geq \mathrm{PF}_{\mathrm{L}}$ & $\mathrm{PF}_{\mathrm{L}}>\mathrm{PF}_{\mathrm{S}}$ \\
\hline$m s e c$ & & \\
$\leq 1.0$ & 33 & 16 \\
$>1.0$ & 33 & 3 \\
\hline
\end{tabular}

\begin{tabular}{|c|c|c|c|c|c|}
\hline \multirow{2}{*}{$\mathrm{ADL}$} & \multicolumn{3}{|c|}{ Number of Units Showing } & \multirow{2}{*}{ Mean $\mathrm{PF}_{\mathrm{s}} \pm \mathrm{SD}$} & \multirow{2}{*}{ Mean $\mathrm{PF}_{\mathrm{L}} \pm \mathrm{SD}$} \\
\hline & $\mathrm{PF}_{\mathrm{S}}=\mathrm{PF}_{\mathrm{L}}$ & $\mathrm{PF}_{\mathrm{S}}>\mathrm{PF}_{\mathrm{L}}$ & $\mathrm{PF}_{\mathrm{L}}>\mathrm{PF}_{\mathrm{s}}$ & & \\
\hline$m s e c$ & & & & & \\
\hline$\leq 1.0$ & 30 & 3 & 16 & $49 \pm 22$ & $60 \pm 34$ \\
\hline $1.1-1.9$ & 11 & 5 & 2 & $46 \pm 18$ & $53 \pm 33$ \\
\hline$\geq 2.0$ & 16 & 1 & 1 & $73 \pm 24$ & $71 \pm 27$ \\
\hline
\end{tabular}



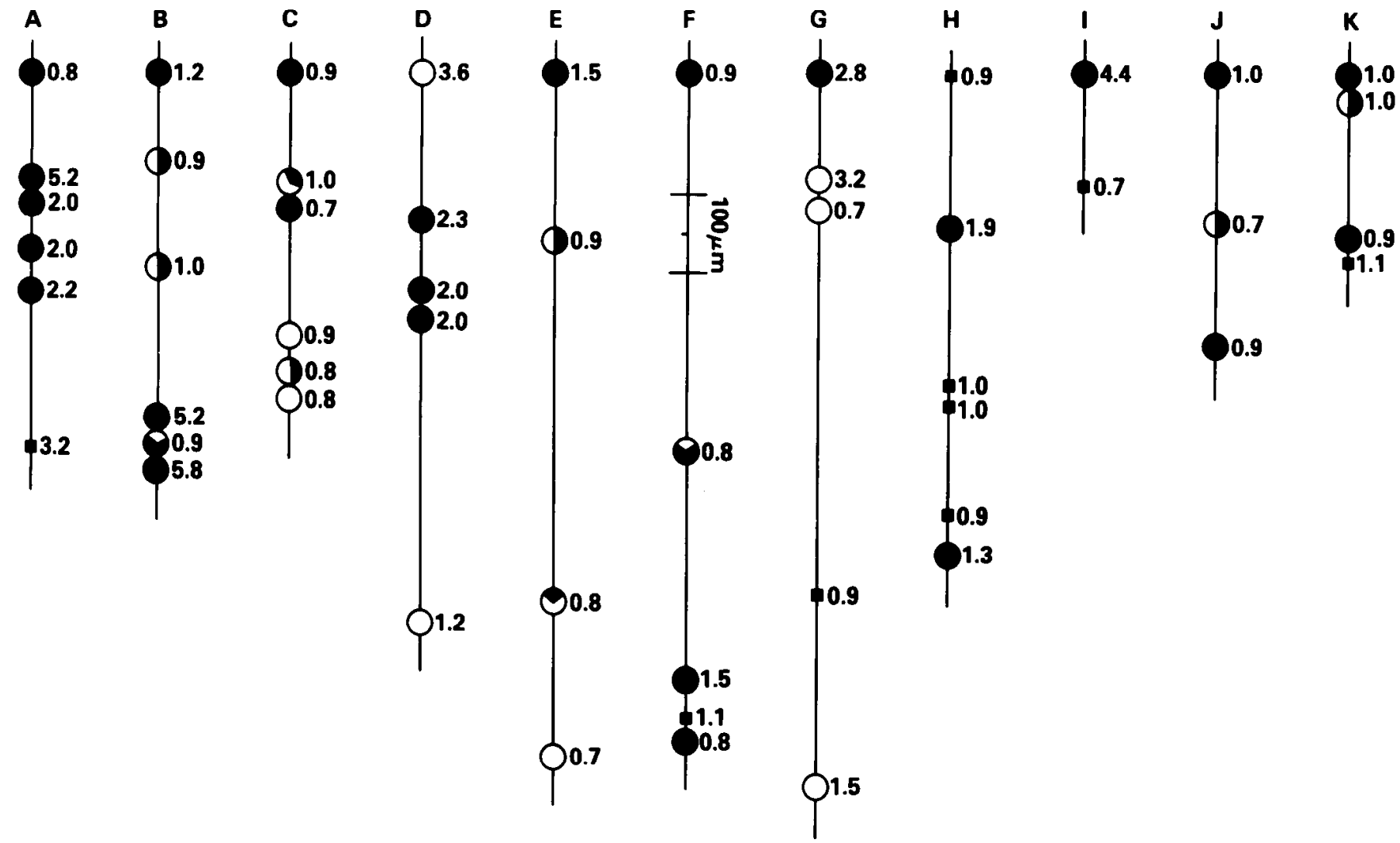

Figure 3. Single microelectrode penetrations $(A$ to $K$ ), schematically drawn and aligned on the first PTN encountered in a track. Intracortical depth-distance from cell to cell as measured by the microdrive (calibration, $100 \mu \mathrm{m}$ in $F$ ). Numbers, ADL in milliseconds; filled circles, PTNs with maximum increase of frequency for the small movement; open circles, PTNs discharging exclusively with the large rapid movement. Partly filled circles indicate the degree to which the PTN peak frequency during large movement is greater than during small movement. (A circle one-half filled means $\mathrm{PF}_{\mathrm{S}} \mathrm{was}_{\mathrm{Salf}}$ of $\mathrm{PF}_{\mathrm{L}}$; a one-third-filled circle means $\mathrm{PF}_{\mathrm{S}}$ was one-third of $\mathrm{PF}_{\mathrm{L}}$, etc.) Small squares, PTNs unrelated to either large or small movement.

TABLE II

Focally located PTNs

The $52 \mathrm{PTN}$ recorded in 11 penetrations in the focus for pronationsupination have been classified according to ADL and to whether they reached maximum frequency with small movement or failed to do so. The difference was statistically significant $\left(\chi^{2}=7.56 ; p<0.001\right)$.

\begin{tabular}{lcc} 
& $\begin{array}{c}\text { Reached Maximum } \\
\text { Frequency with Small } \\
\text { Movement }\end{array}$ & $\begin{array}{c}\text { Failed to Reach Maxi- } \\
\text { mum Frequency with } \\
\text { Small Movement }\end{array}$ \\
\hline $\mathrm{ADL} \leq 1 \mathrm{msec}$ & 9 & 20 \\
$\mathrm{ADL}>1 \mathrm{msec}$ & 16 & 7 \\
\hline
\end{tabular}

classifies the 52 PTNs according to shorter $(\leq 1 \mathrm{msec})$ or longer ( $>1 \mathrm{msec}$ ) ADL and according to whether they reached maximum frequency with small movement (units symbolized by filled circles in Fig. 3) or failed to do so. The group classified as failing to reach maximum frequency with small movement included both the unrelated (small squares in Fig. 3) and LM PTNs (open circles) and those PTNs which reached higher peak frequencies with large movement than with small (partly filled circles in Fig. 3). Table II shows that 16 of the 23 slower PTNs (ADL > $1 \mathrm{msec}$ ) reached maximum frequency with small movement, whereas only 9 of 29 faster PTNs (ADL $\leq 1 \mathrm{msec}$ ) did so. This difference was statistically significant $\left(\chi^{2}=7.56 ; p<0.001\right)$.
The three analyses that now have been considered involved three different ways of looking at the data. In the first analysis, PTNs were subdivided according to whether they were small movement related (SM) or large movement related (LM), and it was seen that the proportion of SM PTNs was greatest in more slowly conducting PTNs and least in PTNs with more rapidly conducting axons. The second analysis considered only the SM PTNs and compared their peak frequencies with large and small movements. This analysis, like the first, showed a relation between ADL and activity with movement: Smaller PTNs discharged just as strongly with small movements as with large, while about one-third of the larger PTNs (even those selected for a significant relation to small movement) discharged more intensely with the large movement than for the small. However, there was much overlap in the behavior of large and small PTNs in all three of these analyses, and it was clear that many of the very largest PTNs used their full dynamic frequency range in association with the rather slight changes of muscular contraction associated with the small movement. Finally, it should be added that the time course of unit discharge with movements (response onset and duration) did not depend on the ADL but rather on the kind of movement performed (see Fig. 2).

$P T N$ responses to limb displacement. In addition to 
being earlier in the recruitment order with voluntary contraction, smaller spinal cord MNs are more susceptible to excitation by afferent input both in man (cf., Desmedt and Godaux, 1975, 1978) and in cat (Henneman et al., 1965). However, a lower responsiveness of small PTNs to afferent impulses, as compared to the reflex responsiveness of large PTNs, has been reported for anesthetized monkeys (Wiesendanger, 1973) and cats (Wettstein and Handwerker, 1970). With these observations in mind, we have examined the relation of ADL and short latency responses of PTNs evoked by pronating or supinating displacements delivered via the handle grasped by the monkey. Figure $4 A$ shows the incidence of sensory responses in the 156 movement-related PTNs divided into three groups according to ADL. This figure parallels Figure 1, where it was shown that $67 \%$ of the smaller PTNs were small movement related, whereas $49 \%$ of the larger PTNs were small movement related. This difference was suggestive but failed to reach statistical significance, and the difference in the incidence of sensory responses within the three different ADL categories (Fig. $4 A$ ) was even slighter.

In spite of the absence of a difference in the incidence of sensory responses in the 156 movement-related PTNs grouped according to ADL (Fig. $4 A$ ), there was a very marked difference in the responsiveness of these same 156 PTNs when they were grouped according to discharge with active movement (Fig. $4 B$ ). Responses occurred in $94 \%(80 / 85)$ of the SM PTNs but in only $31 \%$

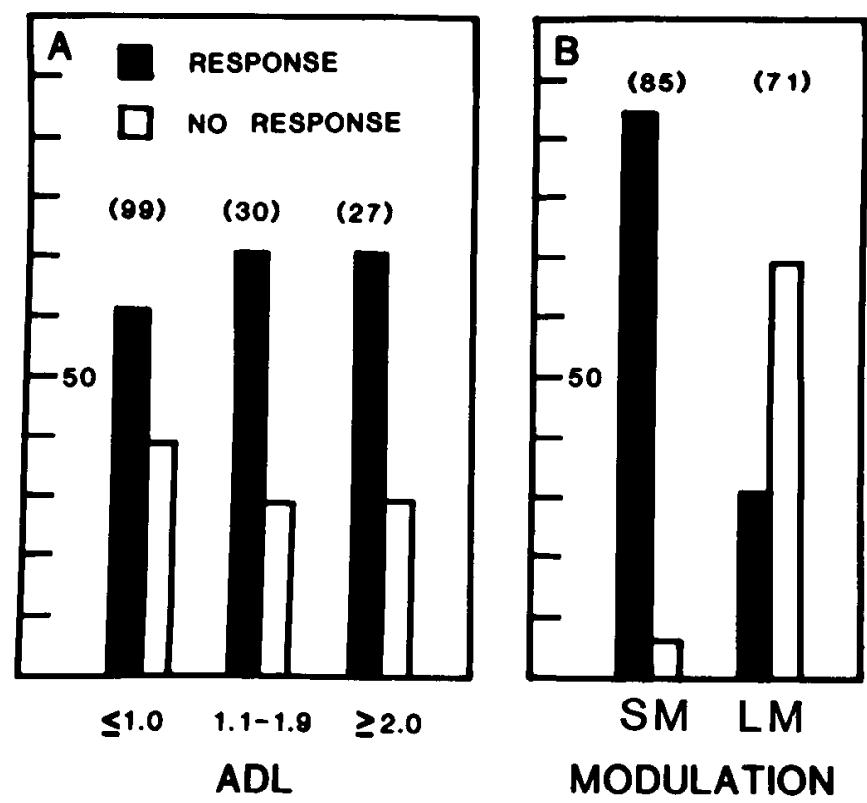

Figure 4. A, Sensory responses in relation to ADL. The 156 PTNs related to movement have been classified according to ADL, and it may be seen that about two-thirds of the units in each category responded (black bars) to a $5^{\circ}$ pronating or supinating displacement, while about one-third failed to respond (white bars). Percentages of responding and non-responding units are shown on ordinate scale. $B$, Sensory responses in relation to SM and LM. 'The same 156 PTNs shown in $A$ are reclassified according to whether they were SM or LM. Within the SM group, 94\% (80/85) showed sensory responses, while in the LM group, only $31 \%(22 / 71)$ showed sensory responses.
$(22 / 71)$ of the LM PTNs. Thus, the presence of a response evoked by passive pronation-supination was very much more common in PTNs related to small active movements than in those related to large movements but unrelated to small movements. A reciprocal relationship to the active supination-pronation, i.e., a decrease of activity for one direction and an increase for the other, was found in 71 of the 85 SM PTNs, and 52 of these also were related reciprocally to both directions of passive supination-pronation displacement, thus being "doubly reciprocal." In contrast, out of the 71 LM PTNs, only 13 were related reciprocally to the active movements and only 3 were also reciprocally responsive to both directions of the passive limb displacement.

\section{Discussion}

In a recent paper on the size principle of motoneuron recruitment during voluntary contractions in man, Desmedt (1981) reviews evidence that smaller motor units discharge with small, slow as well as large, fast movements, while large motor units fail to discharge with small movements but do become active with large movements-especially if these movements are ballistic contractions involving abruptly rising forces.

The results that we have presented now indicate that PTNs exhibit a parallel (though weaker) relation between size and discharge with movements of different amplitude. The data upon which we base this conclusion were obtained from recordings of PTN activity in association with movements performed in a visual pursuittracking paradigm. PTNs were classified as small movement related (SM) when they showed an increase of activity with a small ( 1 to $\left.2^{\circ}\right)$ movement and as large movement related (LM) if they failed to exhibit a statistically significant increase of activity with the small movement but did exhibit an increase with a much larger $\left(20^{\circ}\right)$ and more rapid movement. Our purpose in classifying PTNs as SM and LM was to see if we could find evidence for a relationship between movement-related activity and PTN size, with size being inferred from PTN antidromic response latency (ADL). Two of three different sorts of analyses of 280 precentral PTNs showed statistically significant relations between ADL and movement-related activity. The analysis giving the most highly significant result dealt with a set of 52 PTNs located in a small zone of motor cortex which was judged to be focal for pronation-supination in the two monkeys. Not only did this small region contain many PTNs related to the small movement, but microstimulation within the region evoked pronation or supination movements. Within this focus, 16 of 23 smaller PTNs reached maximum frequency with the small movement, whereas only 9 of the 29 larger PTNs (ADL $\leq 1 \mathrm{msec}$ ) reached peak frequency with small movement. Thus, there was certainly a reflection of a "size principle" in movementrelated activity of motor cortex PTNs.

From single motor unit recordings in man, recruitment of lowest threshold, slowly conducting motoneurons can be inferred to be the main mechanism underlying finely graded movements, while frequency modulation, recruitment of higher threshold motoneurons, and synchronized discharge become more important in more forceful move- 
ments where the orderly recruitment with increasing cell size has been shown to be preserved (Tanji and Kato, 1973a; Milner-Brown et al., 1973a, b; Freund et al., 1975; Büdingen and Freund, 1976; Desmedt and Godaux, 1977). The same general relation seems to be present in weaker form in the motor cortex: One-third of the SM PTNs with shorter ADLs could increase their frequency further with the large rapid movements, and at the same time, larger PTNs were "recruited" with that kind of movement. Furthermore, there was no failure of discharge with large movement in small PTNs which had discharged with small movement. Thus, although our results show that smaller PTNs are engaged most intensely in the control of precise fine movements, it is also true that many of the very largest PTNs also show modulation with very small movements and there appears to be a functional continuum corresponding to the unimodal size distribution of corticospinal cells in area 4 (Jones and Wise, 1977). Thus, there is no simple dichotomy between the large, rapidly conducting PTNs responsible for large phasic movements and the small, slowly conducting PTNs related to small tonic slow movements. The dichotomy between phasic and tonic $\alpha$ motoneurons and the observation that the former attain higher dynamic firing rates than the latter dates back to Granit (Granit et al., 1956, 1957). Under natural conditions in man, however, this subdivision is not apparent, and the change in firing rate per unit force is even larger in slowly conducting small motor units than in the faster conducting ones (Freund et al., 1975; Tanji and Kato, 1973b). An analogous tendency is indicated also for the peak frequencies attained by the small PTNs (Table I).

Limitations in analogies between PTNs and moto neurons. Thus far in this report, we have contrasted the properties of motor cortex PTNs and spinal cord motoneurons without considering a most fundamental difference between them: A given motoneuron sends its axon to motoneurons innervating a number of different muscles. This divergence of the axon of a single PTN to motoneurons of different muscles has been shown by several studies (Asanuma et al., 1979; Shinoda et al., 1979; Fetz and Cheney, 1980).

A second fundamental difference between PTNs and motoneurons is seen when one compares their activity during muscular relaxation. $\alpha$ motoneurons are silent during relaxation of skeletal musculature, but most PTNs (with the exception of the very largest PTNs) are active even under conditions that seem to involve virtually total muscular quiescence (Evarts, 1965). As a result of this steady state discharge, it is impossible to speak of recruitment of PTNs in the way that one can speak of recruitment of MNs and one must instead speak of "modulation" of PTNs with movement.

A third fundamental difference is seen when one compares the nature of the information provided by recordings of single PTNs in motor cortex and single motor units in muscle: Two or more PTNs recorded in a given penetration (even simultaneously recorded) may or may not be related to the same movements and/or muscles, whereas two or more motor units recorded from the same muscle necessarily contribute to the forces and movements with which this muscle is concerned.
These differences between P'T'Ns vis-à-vis motoneurons and motor units have been listed because they call attention to the need for caution in interpreting our results on movement-related PTN activity according to models used in connection with the size principle as exemplified by motor units and motoneurons. If motor cortex PTNs were arranged in homogeneous clusters with each PTN in a cluster projecting monosynaptically to motoneurons of one and only one muscle, then the demonstration of a size principle might have been simple. However, when we consider the three fundamental differences that have heen listed already and then add the fact that many PTNs control interneurons and fusimotor neurons and do not even project to motoneurons, we realize that there are a number of reasons for expecting that demonstration of a size principle in PTNs will not be simple. Thus, the fact that PTNs within the same cluster may project to motoneurons of different muscles means that a small PTN which fails to discharge with a small movement and then discharges with a large movement may merely be concerned with muscles which do not come into play with the small movement but are activated with the large one. EMG recordings in our paradigm showed that the large, high velocity movement involved activity in more muscles as well as more activity in the same muscles that participated in the small movement, and it seems likely that this difference between the large and the small movements complicates interpretation of the results of the present study.

However, while we can see many ways in which the complexities listed above might have reduced the magnitude of the correlations between PTN size and movement-related activity, it is difficult to see how these complexities could have given us falsely high correlations. Indeed, it appears that even our small movement was already too large, and that the paradigm should have involved study of still smaller movements. In retrospect, it is apparent that it would have been a good idea to examine PTN activity in association with movements of ever-decreasing amplitude in order to determine the "threshold" for each individual PTN. Just as a very large part of motor cortex is devoted to control of muscles involved in precise control, it appears that, within regions controlling a given movement, a large proportion of the PTNs is concerned with controlling those motoneurons that are to be recruited first and that exhibit frequency modulation as the strength of the movement is finely graded.

In conclusion, then, the findings that we have reported point to the existence of a relation between PTN size and activity with movement and indicate the need for additional studies in which PTN activity is recorded with movements sufficiently small to allow determination of the "threshold" movement amplitude at which PTN modulation appears.

\section{References}

Asanuma, H., P. Zarzecki, E. Jankowska, T. Hongo, and S. Marcus (1979) Projection of individual pyramidal tract neurons to lumbar motor nuclei of the monkey. Exp. Brain Res. 34: 73-89.

Büdingen, H. J., and H. -J. Freund (1976) The relationship 
between the rate of rise of isometric tension and motor unit recruitment in a human forearm muscle. Pfluegers Arch. 362: 61-67.

Burke, R. E. (1973) On the central nervous system control of fast and slow twitch motor units. In New Developments in Electromyography and Clinical Neurophysiology, J. E. Desmedt, ed., Vol. 3, pp. 69-94, Karger, Basel, Switzerland.

Desmedt, J. E. (1981) The size principle of motoneuron recruitment in ballistic or ramp voluntary contractions in man. In Motor Unit Types, Recruitment Patterns, and Plasticity with Usage in Health and Disease: Progress in Clinical Neurophysiology, J. E. Desmedt, ed., Vol. 9, Karger, Basel, Switzerland, in press.

Desmedt, J. E., and E. Godaux (1975) Vibration-induced discharge patterns of single motor units in the masseter muscle in man. J. Physiol. (Lond.) 253: 429-442.

Desmedt, J. E., and E. Godaux (1977) Ballistic contractions in man: Characteristic recruitment patterns of single motor units of the tibialis anterior muscle. J. Physiol. (Lond.) 264: 673-693.

Desmedt, J. E., and E. Godaux (1978) Mechanism of the vibration paradox: Excitatory and inhibitory effects of tendon vibration on single soleus muscle motor units in man. J. Physiol. (Lond.) 285: 197-207.

Evarts, E. V. (1965) Relation of discharge frequency to conduction velocity in pyramidal tract neurons. J. Neurophysiol. 28: 216-228.

Evarts, E. V. (1968) A technique for recording activity of subcortical neurons in moving animals. Electroenceph. Clin. Neurophysiol. 24: 83-86.

Evarts, E. V., and C. Fromm (1978) The pyramidal tract neuron as a summing point in a closed-loop control system in the monkey. In Cerebral Motor Control in Man: Long Loop Mechanism: Progress in Clinical Neurophysiology J. E. Desmedt, ed., Vol. 4, pp. 56-69, Karger, Basel, Switzerland.

Fetz, E. E., and P. D. Cheney (1980) Postspike facilitation of forelimb muscle activity by primate corticomotoneuronal cells. J. Neurophysiol. 44: 751-772.

Freund, H. -J., and H. J. Büdingen (1978) The relationship between speed and amplitude of the fastest voluntary contractions of human arm muscles. Exp. Brain Res. 31: 1-12.

Freund, H. -J., H. J. Büdingen, and V. Dietz (1975) Activity of single motor units from human forearm muscles during voluntary isometric contractions. J. Neurophysiol. 38: 933-946.
Fromm, C., and E. V. Evarts (1977) Relation of motor cortex neurons to precisely controlled and ballistic movements. Neurosci. Lett. 5: 259-265.

Granit, R., H. -D. Henatsch, and G. Steg (1956) Tonic and phasic ventral horn cells differentiated by post-tetanic potentiation in cat extensors. Acta Physiol. Scand. 37: 114-126.

Granit, R., C. G. Phillips, S. Skoglund, and G. Steg (1957) Differentiation of tonic from phasic alpha ventral horn cells by stretch, pinna and crossed extensor reflexes. J. Neurophysiol. 20: 470-481.

Henneman, E., G. Somjen, and D. D. Carpenter (1965) Functional significance of cell size in spinal motoneurons. J. Neurophysiol. 28: 560-580.

Jones, E. G., and S. P. Wise (1977) Size, laminar and columnar distribution of efferent cells in the sensory-motor cortex of monkeys. J. Comp. Neurol. 175: 391-438.

Milner-Brown, H. S., R. B. Stein, and R. Yemm (1973a) The orderly recruitment of human motor units during voluntary isometric contractions. J. Physiol. (Lond.) 230: 359-370.

Milner-Brown, H. S., R. B. Stein, and R. Yemm (1973b) Changes in firing rate of human motor units during linearly changing voluntary contractions. J. Physiol. (Lond.) 230: 371-390.

Shinoda, Y., P. Zarzecki, and H. Asanuma (1979) Spinal branching of pyramidal tract neurons in the monkey. Exp. Brain Res. 34: 59-72.

Tanji, J., and E. V. Evarts (1976) Anticipatory activity of motor cortex neurons in relation to direction of an intended movement. J. Neurophysiol. 39: 1062-1068.

Tanji, J., and M. Kato (1973a) Recruitment of motor units in voluntary contraction of a finger muscle in man. Exp. Neurol. 40: 759-770.

Tanji, J., and M. Kato (1973b) Firing rate of individual motor units in voluntary contraction of abductor digiti minimi muscle in man. Exp. Neurol. 40: 771-783.

Wettstein, A., and H. O. Handwerker (1970) Afferente Verbindungen zu schnellund langsamleitenden Pyramidenbahnneuronen der Katze. Pfluegers Archiv Gesamte Physiol. Menschen Tiere 320: 247-260.

Wiesendanger, M. (1973) Input from muscle and cutaneous nerves of the hand and forearm to neurones of the precentral gyrus of baboons and monkeys. J. Physiol. (Lond.) 228: 203219. 